\title{
Incidence of persistent symptoms after laparoscopic cholecystectomy: a prospective study
}

\author{
W Luman, W H Adams, S N Nixon, I M Mcintyre, D Hamer-Hodges, G Wilson, \\ K R Palmer
}

\begin{abstract}
Background and Aims-Laparoscopic cholecystectomy is the standard treatment for symptomatic gall stone disease. This study aimed to assess the effect of the operation on patients' symptoms.

Methods-One hundred consecutive patients undergoing laparoscopic cholecystectomy between June 1994 and June 1995 were evaluated using standard questionnaires examining demographic details, indication for laparoscopic cholecystectomy, characteristics of pain, and other associated dyspeptic and colonic symptoms. A history of psychiatric disturbances and of hysterectomy were also recorded. The same questionnaires were administered again six months after the operation. Operation notes and histo-
\end{abstract} logical reports were reviewed.

Results-Three patients were converted to open surgery and were excluded from analysis. The median age of the remaining 97 patients was $50.9(19-85)$ years; 19 were men. There was one complication each of bleeding and biliary leak. Indications for laparoscopic cholecystectomy were biliary type pain (66 patients) and complicated gall stone disease (acute cholecystitis 21 , cholestatic jaundice six, and pancreatitis four). Thirteen patients $(13 \%)$ had persistent pain and two $(3 \%)$ developed diarrhoea at follow up. Only one patient with persistent pain after laparoscopic cholecystectomy originated from the complicated gall stone disease group. Logistic discriminant analysis showed that bloating $(p<0.001)$, constipation $(p<0.05)$, and previous and current use of psychotrophic drugs $(p<0.001)$ were significantly more common among those with a poor outcome after laparoscopic cholecystectomy. Heartburn was unaffected. Of patients with persistent symptoms after cholecystectomy $77 \%$ had no or mild histological changes of cholecystitis as compared with $30 \%$ in the pain free group.

Conclusions-The incidence of persistent pain after laparoscopic cholecystectomy was $13 \%$. Abdominal bloating and psychiatric medications were predictive for persistence of pain after laparoscopic cholecystectomy.

(Gut 1996; 39: 863-866)

Keywords: postlaparoscopic cholecystectomy, persistence of pain.
Since its introduction in 1987, laparoscopic cholecystectomy has become the standard treatment for symptomatic gall stone disease. Its advantages over open surgery are well documented. ${ }^{1-3}$

A few patients continue to have gastrointestinal symptoms after laparoscopic cholecystectomy. The term 'postcholecystectomy syndrome' has been used to describe this condition although the term 'persistent postcholecystectomy symptoms' is a more accurate description. The reported incidence of persistent symptoms after cholecystectomy varies widely. Studies on the symptomatic outcome after laparoscopic cholecystectomy have reported successful relief of symptoms in $70 \% \%^{4}$ to $95 \%$ of patients ${ }^{6}{ }^{7}$ but the characteristics of patients who continue to experience pain after surgery is poorly defined. Furthermore, no study has prospectively analysed symptoms before and after laparoscopic cholecystectomy.

\section{Method}

PATIENTS

One hundred unselected consecutive patients admitted for laparoscopic cholecystectomy between June 1994 to June 1995 were recruited into the study. All patients had either been placed on an elective operating list after assessment by surgical teams, or underwent urgent surgery after admission to hospital for acute gall stone related emergencies. The diagnosis of cholelithiasis was confirmed by ultrasonography in all cases. Patients were excluded if open cholecystectomy had been planned or if they were unable to cooperate in answering the questionnaires. Indications for cholecystectomy and details of investigations performed before surgery were obtained from medical notes.

\section{QUESTIONNAIRES}

The symptom profile of the patients was evaluated by one of us (WL) not involved in surgical management. A standard questionnaire examined characteristics of pain (site, duration, frequency, quality, periodicity, and precipitating and relieving factors), other dyspeptic symptoms (nausea, vomiting, heartburn, food intolerance, and early satiety), and colonic symptoms (bloating, constipation, diarrhoea). Histories of hysterectomy and psychiatric disturbances were also evaluated. Questionnaires were administered to patients before surgery and six to 10 months (median seven) 
TABLE I Indications for laparoscopic cholecystectomy and duration of symptoms

\begin{tabular}{lcc}
\hline Baseline characteristics & $\begin{array}{c}\text { Asymptomatic } \\
(n=84)\end{array}$ & $\begin{array}{c}\text { Symptomatic } \\
(n=13)\end{array}$ \\
\hline Indication: & & \\
$\quad$ Biliary type pain & 54 & $12^{\star}$ \\
Complicated gall stone disease & 30 & 1 \\
$\quad$ Acute cholecystitis & $(20)$ & $(1)$ \\
$\quad$ Cholestatic jaundice & $(6)$ & $(0)$ \\
$\quad$ Pancreatitis & $(4)$ & $(0)$ \\
Duration of symptoms & 54 & 10 \\
$\quad$ Less than 6 months & 30 & 3 \\
More than 6 months & 30 & \\
\hline
\end{tabular}

after surgery. Patients were followed up in routine outpatient review or by telephone interview. Their notes were reviewed for operation details, postoperative morbidity, complications, and gall bladder histology, although this information was unavailable to WL at the time of assessment. Laparoscopic cholecystectomy was carried out as a four trocar technique with electrocautery dissection. Intraoperative cholangiography was not routinely performed. Patients with a history of jaundice, abnormal liver function tests, dilated common bile duct, and pancreatitis underwent preoperative endoscopic retrograde cholangiopancreatography (ERCP) and sphincterotomy.

STATISTICAL ANALYSIS

Simple comparisons of preoperative symptoms between patients with persistent symptoms after laparoscopic cholecystectomy and those with successful outcome were performed $\left(\chi^{2}\right.$; $\mathrm{p}<0.05$ was accepted as significant).

TABLE II Incidence of pain characteristics

\begin{tabular}{|c|c|c|c|c|}
\hline \multirow[t]{2}{*}{ Pain characteristics } & \multicolumn{2}{|c|}{ No of patients (\%) } & \multirow[t]{2}{*}{ Frequency (\%) } & \multirow[t]{2}{*}{$p$ Value } \\
\hline & Asymptomatic & Symptomatic & & \\
\hline \multicolumn{5}{|l|}{ Site: } \\
\hline Upper abdomen & $77(92)$ & $13(100)$ & 93 & NS \\
\hline Lower abdomen & $7(8)$ & $0(0)$ & 7 & NS \\
\hline Radiation to back & $49(58)$ & $11(85)$ & 60 & NS \\
\hline \multicolumn{5}{|l|}{ Quality: } \\
\hline Sharp & $32(38)$ & $6(46)$ & 38 & NS \\
\hline Cramp & $18(21)$ & $1(8)$ & 19 & NS \\
\hline Burning & $6(7)$ & $2(15)$ & 8 & NS \\
\hline Crushing & $4(5)$ & $1(8)$ & 5 & NS \\
\hline \multirow{2}{*}{\multicolumn{5}{|c|}{ Periodicity: }} \\
\hline & & & & \\
\hline Constant & $56(67)$ & $7(54)$ & 65 & NS \\
\hline Colic & $28(33)$ & $6(46)$ & 35 & NS \\
\hline \multicolumn{5}{|l|}{ Duration (min): } \\
\hline$<30$ & $50(59)$ & $9(69)$ & 61 & NS \\
\hline$>30$ & $34(41)$ & $4(31)$ & 39 & NS \\
\hline \multicolumn{5}{|l|}{ Frequency(per week): } \\
\hline$>1$ attack & $38(45)$ & $8(61)$ & 47 & NS \\
\hline$<1$ attack & $46(55)$ & $5(39)$ & 53 & NS \\
\hline
\end{tabular}

TABLE III Incidence of dyspeptic and colonic symptoms

\begin{tabular}{|c|c|c|c|c|}
\hline \multirow[t]{2}{*}{ Symptoms } & \multicolumn{2}{|c|}{ No of patients (\%) } & \multirow[t]{2}{*}{ Frequency (\%) } & \multirow[t]{2}{*}{ p Value } \\
\hline & Asymptomatic & Symptomatic & & \\
\hline \multicolumn{5}{|l|}{ Dyspepsia: } \\
\hline Nausea & $50(60)$ & $8(62)$ & 60 & NS \\
\hline Vomiting & $28(33)$ & $3(23)$ & 32 & NS \\
\hline Heartburn & $29(35)$ & $4(31)$ & 34 & NS \\
\hline Early satiety & $14(17)$ & $4(31)$ & 18 & NS \\
\hline Food intolerance & $44(52)$ & $8(31)$ & 54 & NS \\
\hline \multicolumn{5}{|l|}{ Colonic symptoms: } \\
\hline Bloating & $36(43)$ & $12(92)$ & 50 & 0.001 \\
\hline Constipation & $7(8)$ & $10(77)$ & 11 & $<0.05$ \\
\hline Diarrhoea & $3(6)$ & $2(15)$ & 5 & NS \\
\hline
\end{tabular}

Analysis of the associated symptoms was subdivided into dyspeptic and colonic symptoms. Gall bladder histology was classified as normal, mild (mild chronic infiltrate confined to lamina propria), moderate, and severe (changes of cholecystitis with severe acute and chronic inflammatory infiltrate, fibrosis, and atrophy of gall bladder wall).

\section{Results}

Three patients were excluded from the final analysis because the planned laparoscopic cholecystectomy was converted to open surgery. One patient had an empyema of the gall bladder and two patients had dense adhesions. The remaining 97 patients were all successfully followed up.

There were 19 men $(20 \%)$ and 78 women $(80 \%)$. The median age was 50.9 (range 19-85) years. There was one complication each of biliary leak and bleeding. Two other patients reported new onset of diarrhoea after laparoscopic cholecystectomy. Thirteen patients $(13 \%)$ reported pain similar to that present before surgery and were defined as the symptomatic group. Patients who became pain free were defined as the asymptomatic group. All of the patients with persistent symptoms had normal postoperative liver function tests and ultrasound scans; five patients had a normal ERCP (no other patient in the study had ERCP). Two patients had been found to have Helicobacter pylori positive duodenal ulcer disease on gastroscopy. Relief of symptoms was obtained after eradication of the organism.

PREOPERATIVE CHARACTERISTICS

Table I shows the indications for surgery and duration of symptoms. Sixty six patients underwent laparoscopic cholecystectomy because of biliary type pain and 31 for complicated gall stone disease. Patients with biliary type pain presented with recurrent attacks of right hypochondriac pain which radiated to the back. In each patient this pain was episodic with exacerbation of several hours. Most of these patients were free of pain between exacerbation, but a few had persistent discomfort between the acute attacks. Patients with complicated gall stone disease underwent laparoscopic cholecystectomy because of acute cholecystitis, cholestatic jaundice or acute pancreatitis.

Most patients complained of upper abdominal pain (either epigastric or right hypochondrium) (Table II). The duration and frequency and the quality and periodicity of pain were equally distributed in the two groups. Table III shows the prevalence of preoperative dyspeptic and colonic symptoms. The common dyspeptic symptoms were nausea $(60 \%)$, food intolerance $(54 \%)$, and heartburn $(30 \%)$. Most patients noted fatty food intolerance. Of the colonic symptoms, bloating $(50 \%)$ was the most common.

The thirteen patients who continued to complain of pain after laparoscopic cholecystectomy differed in several respects from those 
TABLE IV Incidence of abdominal surgery, psychiatric medications, and histological findings

\begin{tabular}{lllll}
\hline Symptoms & \multicolumn{2}{l}{ No of patients (\%) } & Frequency (\%) & p Value \\
\cline { 2 - 3 } & $\begin{array}{l}\text { Asymptomatic } \\
(n=84)\end{array}$ & $\begin{array}{l}\text { Symptomatic } \\
(n=13)\end{array}$ & & \\
\hline Abdominal surgery: & $50(60)$ & $7(54)$ & 59 & NS \\
No surgery & $8(10)$ & $1(8)$ & 9 & \\
Hysterectomy & $26(31)$ & $5(38)$ & 32 & $<0.001$ \\
Other surgery & $13(15)$ & $8(62)$ & 22 & $<0.01$ \\
Psychotrophic drugs & $30(36)$ & $10(77)$ & 41 & \\
Gall bladder histology: & $54(64)$ & $3(23)$ & 59 & $<0.05$ \\
$\quad$ Normal/mild & $1(1)$ & $5(39)$ & 17 & \\
Moderate/severe & 0 & $5(39)$ & 5 & \\
Preoperative investigations: & Gastroscopy & & & \\
Barium enema & & & & \\
\hline
\end{tabular}

who had a successful outcome. All but one of the 13 patients had a history of biliary type pain, and only one underwent surgery because of acute cholecystitis $(p<0.05$, Table I). These patients had also been subjected to more preoperative investigations (gastroscopy or barium enema) than those with a successful outcome $(p<0.05$, Table IV). Previous hysterectomy was not as common in those with pain after cholecystectomy. Most patients with successful surgical outcome had histological evidence of moderate or severe cholecystitis $(64 \%)$, whereas the group with persistent pain usually had normal or mild changes of cholecystitis $(77 \%)$.

As shown in Tables III and IV, bloating $(p<0.001)$, constipation $(p<0.05)$, and previous or current consumption of psychotrophic drugs $(p<0.001)$ were significantly more common in the poor outcome group. Psychotrophic drugs were defined as either current or previous medications with antidepressant or anxiolytic drugs. Eight patients were taking psychiatric drugs (six antidepressant, two anxiolytic) at the time of surgery.

\section{POSTOPERATIVE CHARACTERISTICS}

Table $\mathrm{V}$ shows the postoperative characteristics. Heartburn was not cured by laparoscopic cholecystectomy although most patients did not think that this was a failure of cholecystectomy as they did not expect heartburn to be relieved by surgery. We did not detect any new development of heartburn after cholecystectomy. The cure rates for nausea and early satiety were in excess of $80 \%$. The reported incidence of nausea, vomiting, and early satiety after surgery was largely confined to patients who continued to experience pain

TABLE v Prevalence of preoperative and postoperative symptoms

\begin{tabular}{llrl}
\hline Symptom & \multicolumn{2}{l}{ No of patients } & \multirow{2}{*}{${ }^{\star}$ Cure rate (\%) } \\
\cline { 2 - 3 } & Preoperative & Postoperative & \\
\hline Nausea & 50 & 3 & 94 \\
Vomiting & 28 & 10 & 65 \\
Heartburn & 29 & 28 & 3 \\
Early satiety & 14 & 2 & 85 \\
Food intolerance & 44 & 9 & 80 \\
Bloating & 36 & 11 & 69 \\
Constipation & 7 & 7 & 0 \\
Diarrhoea & 5 & 7 & 0 \\
\hline
\end{tabular}

${ }^{\star}$ Cure rate is defined as the proportion of those with a given symptom preoperatively who did not have the symptom postoperatively. after surgery. The incidence of food intolerance was also low after laparoscopic cholecystectomy but most patients continued on low fat diet after surgery.

\section{Discussion}

In this prospective study of symptoms after laparoscopic cholecystectomy, the incidence of persistent symptoms was $13 \%$. Preoperative abdominal bloating, constipation, and the use of psychotrophic drugs were significantly more common in these patients.

Studies that have assessed symptomatic outcome after open cholecystectomy have given varying results. Ros and Gambon evaluated 93 patients two years after cholecystectomy. ${ }^{8}$ Only 53 patients were completely free of symptoms. Konsten $e t a l^{9}$ followed up over 300 Dutch patients through postal questionnaires to their general practitioners at a median interval of 10 years after cholecystectomy and reported symptoms in $18 \%$. Gilliland and Traverso followed up over 600 patients for a mean of 45 months and found that $88 \%$ of patients had complete symptomatic relief after cholecystectomy. ${ }^{10}$ Around $1 \%$ of patients reported occasional diarrhoea. Dyspepsia was the most common residual symptom after cholecystectomy in this subset, occurring in $32 \%$.

The varying incidence of persistent symptoms after cholecystectomy can be ascribed to the varying methods of evaluation, wording of questionnaires, and patient case mix. Abdominal pain, heartburn, nausea, flatulence, and other dyspeptic symptoms are variously recorded and words such as dyspepsia and flatulence mean many different things to different patients.

There have been few studies which have examined symptoms after laparoscopic cholecystectomy. In a three month follow up of 52 patients, Peters et al reported that $77 \%$ of patients considered their symptoms to have been cured by the procedure. ${ }^{5}$ In a comparative study of open and laparoscopic cholecystectomy, Velpen et al reported that $95 \%$ of patients considered that they had obtained overall symptomatic improvement. ${ }^{7}$ Qureshi et al analysed patients' perceptions of postoperative symptoms and global satisfaction. ${ }^{4}$ They noted that $25 \%$ of patients complained of more than two symptoms postoperatively but $84 \%$ considered the procedure to be a complete success. In a study of an earlier cohort of patients from our hospital, Wilson and Macintyre evaluated symptomatic outcome of 115 patients a year after laparoscopic cholecystectomy and compared the outcome with 200 patients who had undergone the open procedure. Over $90 \%$ of patients in both groups considered the procedures to have been successful in achieving symptomatic relief. ${ }^{6}$ McMahon et al also reported that over $90 \%$ of patients were improved by the operation. ${ }^{11}$ None of these studies assessed patients' symptoms in a prospective manner; only patients' postoperative symptoms were evaluated and patients were either expected to list preoperative symptoms, ${ }^{4}$ or their case notes were reviewed. 
The incidence of persistent postcholecystectomy symptoms reported in this series is similar to that reported for open cholecystectomy ${ }^{10}$ but is higher than that reported by Wilson and Macintyre. ${ }^{6}$ These authors found that $94 \%$ of patients considered the operation to have cured or improved their symptoms and only $6.6 \%$ complained of having abdominal pain every day or most days after cholecystectomy. This may be because $34 \%$ of patients in their series had acute cholecystitis compared to $20 \%$ in the current series and this higher proportion may help to account for the better results. ${ }^{6}$

Patients with atypical biliary pain usually underwent extensive upper gastrointestinal or colonic investigations before being referred for surgery. Despite this cautious approach, two patients with persistent cholecystectomy pain were subsequently found to have duodenal ulcer disease associated with $H$ pylori. It is noteworthy that only one patient with persistent pain after cholecystectomy came from the group with complicated gall stone disease. Patients in the symptomatic group also underwent more investigations than those in the asymptomatic group.

Unlike Velpen et $a l^{7}$ we did not detect symptomatic relief from heartburn or de novo development of this symptom after laparoscopic cholecystectomy. The cure rate for nausea, vomiting, and early satiety was excellent as also reported by Velpen et $\mathrm{al}^{7}$

Preoperative abdominal bloating, constipation, and the use of psychotrophic drugs were significantly more common in the symptomatic group. Patients with persistent pain after laparoscopic cholecystectomy had a higher prevalence of normal or only minimally inflamed gall bladder histology than the asymptomatic group. These findings suggest that persistent abdominal pain after laparoscopic cholecystectomy may have been due to underlying irritable bowel syndrome and was unrelated to gall stones. Indeed, McMahon et al showed that patients with the 'postcholecystectomy syndrome' tended to be anxious and depressed ${ }^{11}$ and it is well known that patients with irritable bowel syndrome and 'functional dyspepsia' tend to be neurotic, anxious, and depressed. ${ }^{12} 13$

The rate of cholecystectomy has increased in Scotland in parallel with the introduction of the laparoscopic approach. ${ }^{14}$ The reasons for this increase are not known but it could be due to reduced surgical threshold, and unnecessary surgery in patients who are best regarded as having 'silent gall stones' may have been increasingly undertaken. It is therefore important that appropriate indications for cholecystectomy are used. For example, heartburn or non-specific dyspepsia are not adequate reasons for laparoscopic cholecystectomy and our study confirms that these symptoms are not alleviated by the operation. Furthermore, surgeons should be aware that the subgroup of patients whose preoperative symptoms include abdominal bloating and altered bowel habit and who have required psychotrophic drugs may in fact have 'silent gall stones' and irritable bowel syndrome. Such patients are unlikely to benefit from laparoscopic cholecystectomy.

1 Grace PA, Qureshi A, Coleman JE. Reduced postoperative hospitalization after laporoscopic cholecystecomy. $\mathrm{Br} \mathcal{F}$ Surg 1991; 78: 160-2.

2 Nathanson LK, Shimi S, Cushieri A. Laporoscopic cholecystectomy: the Dundee technique. Br f Surg 1991; 8: $155-9$.

3 Macintyre IMC, Wilson RG. Laporoscopic cholecystectomy. Br F Surg 1993; 80: 552-9.

4 Qureshi MA, Brindley NM, Osborne DH, et al. Postcholecystectomy symptoms after laporoscopic cholecystectomy. Ann R Coll Surg Engl 1993; 75: 349-53.

5 Peters JH, Ellison C, Innes JE. Safety and efficacy of laporoscopic cholecystectomy. A prospective analysis of 100 initial patients. Ann Surg 1991; 213: 3-12.

6 Wilson RG, MacIntyre IM. Symptomatic outcome after laporoscopic cholecystectomy. $\mathrm{Br} \mathcal{F}$ Surg 1993; 89: laporoscopic 439 .

7 Velpen GCV, Shimi SM, Cushieri A. Outcome after cholecystectomy for symptomatic gall stone disease and effect of surgical access: laparoscopic $v$ open approach Gut 1993; 34: 1448-51.

8 Ros E, Zambon D. Postcholecystectomy symptoms. A prospective study of gall stone patients before and two years after surgery. Gut 1987; 28: 1500-4.

9 Kinsten J, Gouma DJ, von Meyenfeldt MF, Menheere P Long-term follow-up after open cholecystectomy. $\mathrm{Br} \mathcal{F}$ Surg 1993; 80: 100-2.

10 Gilliland TM, Traverso LW. Modern standards for comparison of cholecystectomy with alternative treatments for symptomatic cholelithiasis with emphasis on long term relief of symptoms. Surg Gynaecol Obstet 1990; 170: relief of

11 McMahon AJ, Ross S, Baxter JN, et al. Symptomatic outcome 1 year after laparoscopic and minilaparotomy cholecystectomy: a randomised trial. Br f Surg 1995; 82 1378-82.

12 Tallet NJ, Fung LH, Gilligan IJ, McNeil D, Piper DW. Association of anxiety, neuroticism, amd depression with dyspepsia of unknown cause. Gastroenterology 1986; 90 886-92.

13 Tangen Haug T, Wilhelmsen I, Besrtad A, Ursin H. Life events and stress in patients with functional dyspepsia compared with patients with duodenal ulcer and healthy controls. Scand $\mathscr{f}$ Gastroenterol 1995; 30: 524-30.

14 Lam CM, Murray FE, Cuschieri A. Increased cholecystectomy rate after the introduction of laparoscopic cholecystectomy in Scotland. Gut 1996; 38: 282-4. 